\title{
Brief Review
}

\section{Brief review: The Cobra Perilaryngeal Airway (CobraPLA®) and the Streamlined Liner of Pharyngeal Airway (SLIPA ${ }^{\mathrm{TM}}$ ) supraglottic airways} [Article de synthèse court: Les dispositifs supraglottiques Cobra Perilaryngeal Airway (CobraPLA®) et Streamlined Liner of Pharyngeal Airway (SLIPA $\left.\left.{ }^{\mathrm{TM}}\right)\right]$

Hedieh Hooshangi MD, David T. Wong MD

Purpose: To summarize the published literature related to two, new supraglottic airways (SGAs): the Cobra Perilaryngeal Airway (CobraPLA $\left.{ }^{\circledR}\right)$ and the Streamlined Liner of Pharyngeal Airway (SLIPA ${ }^{\mathrm{TM}}$ ).

Source: We identified original articles, through searches on Medline and PubMed, using the keywords 'Cobra', 'CobraPLA', 'Cobra-PLA', 'PLA', and 'SLIPA'.

Principal findings: Searches identified 28 publications evaluating the CobraPLA ${ }^{\circledR}$, six of which were randomized, controlled trials. Five publications evaluated the SLIPA ${ }^{\mathrm{TM}}$, two of which were randomized, controlled trials. Studies compared the CobraPLA ${ }^{\circledR}$ with a number of SGAs, in regards to both efficacy and safety. While the CobraPLA ${ }^{\circledR}$ is comparable to the laryngeal mask airway (LMA) Classic $^{\mathrm{TM}}$, with respect to insertion times and the incidence and severity of sore throat, the CobraPLA $\mathbb{}$ is superior, with respect to airway sealing pressure, and has been used successfully in patients with limited mouth opening and limited head extension. Insertion times, first insertion success rates, recovery times, and hemodynamic responses, associated with insertion of the SLIPA ${ }^{\mathrm{TM}}$, are similar to those of the LMA Proseal ${ }^{\mathrm{TM}}$. Although the SLIPA ${ }^{\mathrm{TM}}$ has a unique reservoir chamber to contain regurgitated fluid, the extent of its protection against pulmonary aspiration has not been established in the clinical setting.

Conclusion: Both the CobraPLA ${ }^{\circledR}$ and the SLIPA ${ }^{\mathrm{TM}}$ are intended for use during short procedures under general anesthesia, and have comparable efficacy and complication rates in comparison to the LMA Classic ${ }^{\mathrm{TM}}$. Both airways may be considered as primary SGA devices, and the CobraPLA ${ }^{\circledR}$ may be also be used as a rescue airway device.

CAN J ANESTH 2008/55:3/pp 177-185

Objectif : Faire une synthèse de la littérature publiée au sujet de deux nouveaux dispositifs supraglottiques (SGA) : le CobraPLA ${ }^{\circledR}$ (Cobra Perilaryngeal Airway) et le SLIPA ${ }^{\mathrm{TM}}$ (Streamlined Liner of Pharyngeal Airway).

Source : Des recherches sur Medline et PubMed nous ont permis d'identifier des articles originaux en utilisant les mots clés 'Cobra', 'CobraPLA', 'Cobra-PLA', 'PLA', et 'SLIPA'.

Constatations principales : Les recherches effectuées ont identifié 28 articles publiés évaluant le CobraPLA®, dont six étaient des études randomisées contrôlées. Les études ont comparé l'efficacité et l'innocuité du CobraPLA® à plusieurs autres dispositifs supraglottiques. Les recherches montrent que le CobraPLA ${ }^{\circledR}$, bien qu'équivalent au masque laryngé (LMA) Classic ${ }^{\mathrm{TM}}$ en ce qui concerne les temps d'insertion et l'incidence et la sévérité des maux de gorge, lui est supérieur en ce qui concerne la pression d'étanchéité dans les voies aériennes. De plus, le CobraPLA ${ }^{\circledR}$ a été utilisé avec succès chez des patients présentant une ouverture buccale limitée ainsi qu'une extension de la tête limitée. Les temps d'insertion, les taux de réussite de la première insertion, les temps de récupération et les réactions hémodynamiques associées à l'insertion du SLIPA ${ }^{\text {TM }}$ présentent des résultats semblables à ceux obtenus avec le masque

From the Department of Anesthesiology, Toronto Western Hospital, University Health Network, University of Toronto, Toronto, Ontario, Canada.

Address correspondence to: Dr. David T. Wong, Department of Anesthesiology, MC 2-405, Toronto Western Hospital, 399 Bathurst Street, Toronto, Ontario M5T 2S8, Canada. Phone: 416-603-5118; Fax: 416-603-6494; E-mail: david.wong@uhn.on.ca

This work is supported, in part, by the Department of Anesthesiology, Toronto Western Hospital, University Health Network, University of Toronto.

The authors declared that they do not have any conflict of interest or competing interests related to the airway devices reviewed in this manuscript.

Accepted for publication March 20, 2007.

Revision accepted December 13, 2007. 
laryngé LMA Proseal ${ }^{\mathrm{TM}}$. Bien que le masque SLIPA ${ }^{\mathrm{TM}}$ comprenne une chambre réservoir spéciale servant à contenir le fluide régurgité, l'étendue de sa protection contre l'inhalation pulmonaire n'a pas été démontrée dans un contexte clinique.

Conclusion : Le CobraPLA® et le SLIPA ${ }^{\mathrm{TM}}$ sont tous deux conçus pour une utilisation dans le cadre de procédures brèves sous anesthésie générale, et présentent des caractéristiques d'efficacité et des taux de complication comparables au masque laryngé LMA Classic $^{\top M}$. Ces deux dispositifs peuvent être considérés comme des outils de première intention, et le CobraPLA ${ }^{\circledR}$ peut également être utilisé comme instrument de sauvetage.

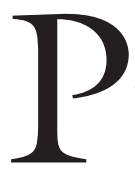
RIOR to the late 1980s, there were two primary choices for airway management in patients undergoing general anesthesia; endotracheal intubation or face mask ventilation. Since the introduction of the laryngeal mask airway (LMA) in the late 1980s, supraglottic airways (SGAs) have been used in millions of patients, for management of both normal and difficult airways for patients under general anesthesia, with an excellent record of efficacy and safety. As a salvage strategy for patients with difficult airways, the American Society of Anesthesiologists and the Difficult Airway Society of the United Kingdom have both recommended use of the LMA Classic ${ }^{\mathrm{TM}}$ in the cannot intubate, cannot mask-ventilate situation. Accordingly, the LMA Classic $^{\mathrm{TM}}$ has become, in recent years, both a primary airway and a rescue device in cannot intubate, cannot ventilate events. ${ }^{1-4}$

Over the past decade, several new SGA devices have been introduced as alternatives to the LMA Classic ${ }^{\mathrm{TM}} .{ }^{5}$ Several factors have stimulated the continuing development of supraglottic airways, in what has evolved into a highly competitive marketplace for the manufacturers of these devices. While insertion success rates with the LMA Classic ${ }^{\mathrm{TM}}$ are high, it is nevertheless important to have the availability of alternative SGAs, in the event of failure of the first device. ${ }^{6}$ Moreover, the need for disposable devices, to avoid transmission of infective organisms and prion proteins, cannot be ignored. ${ }^{7}$

The clinical use of the LMA Classic ${ }^{\mathrm{TM}}$ has been extensively reviewed. ${ }^{6}$ Several disposable variants of the SGA have been developed including: the Ambu® AuraOnce ${ }^{\mathrm{TM}}$ Laryngeal Mask (Ambu Inc, Glen Burnie, MD, USA); Portex ${ }^{\circledR}$ Soft-Seal ${ }^{\circledR}$ Laryngeal Mask (Smiths Medical International Limited, Hythe, UK); and the air- $\mathrm{Q}^{\mathrm{TM}}$ (Mercury Medical, Clearwater, FL, USA). Their designs, configuration, and usage are similar to the LMA Classic ${ }^{\mathrm{TM}}$. There are also several SGAs, similar to the LMA Classic ${ }^{\mathrm{TM}}$, whose primary indication is to facilitate passage of an endotracheal tube.
Examples include the Intubating LMA ${ }^{\mathrm{TM}}$ (LMA North America Inc., San Diego, CA, USA) and the Cookgas ${ }^{\circledR}$ ILA (Mercury Medical, Clearwater, FL, USA). These devices will not be considered in this article.

Four SGAs exist, which are quite different in design compared to the LMA Classic ${ }^{\mathrm{TM}}$. These airway devices include: the Combitube ${ }^{\circledR}$ (Tyco-Kendall-Sheridan, Mansfield, MA, USA); the Laryngeal Tube LT (VBM Medizintechnik GmbH, Sulz, Germany); the Cobra Perilaryngeal Airway-CobraPLA ${ }^{\circledR}$ (Engineered Medical System, Indianapolis, IN, USA); and the Streamlined Liner of Pharyngeal Airway -SLIPA ${ }^{\mathrm{TM}}$ (SLIPA Medical Limited, London, UK). As the Combitube ${ }^{\circledR}$ and Laryngeal Tube LT have been recently reviewed elsewhere, ${ }^{8,9}$ this review focuses on the latter two devices.

We identified relevant articles through searches using the following keywords on both Medline and Pubmed: 'Cobra', 'Cobra PLA', 'Cobra-PLA', 'PLA', 'SLIPA' ${ }^{\mathrm{TM}}$, 'Perilaryngeal airway(s)', 'extraglottic airways', 'SGA', and 'Supraglottic airway(s). We completed the search for English language papers published during the years 1996 to 2006; and we hand-searched reference lists of these articles for additional sources. Twenty-six publications were identified for the CobraPLA ${ }^{\circledR}$, six of which were randomized, controlled trials. Five publications were identified for the SLIPA ${ }^{\mathrm{TM}}$; two of these were randomized, controlled trials.

The purpose of this brief review was to compare the design and the technical features, as well as the cumulated, clinical experience between the CobraPLA $\AA$ and the SLIPA ${ }^{\mathrm{TM}}$. The efficacy and the safety of both of these devices were compared to the LMA Classic ${ }^{\mathrm{TM}}$.

\section{The CobraPLA® \\ Description}

The CobraPLA $\AA$ is a cuffed, disposable, sterile, and latex free SGA. ${ }^{5,10,11}$ It is made of polyvinyl chloride and has three main parts: a head, a circumferential pharyngeal cuff, and a breathing tube (Figure 1). This SGA is available in eight sizes, and can be used for neonates as well as for infants. The internal diameter of the breathing tube for adults has a range of 10.5 to $12.5 \mathrm{~mm}$ and all sizes can be attached to a standard, $15 \mathrm{~mm}$ internal diameter connector. Cuff volume ranges from $<8 \mathrm{~mL}$, for neonates, to $<65$ and $<85$ $\mathrm{mL}$, for small and large adults, respectively. An endotracheal tube of size 8 can be advanced through the CobraPLA® sizes 4-6 (Table I). ${ }^{\mathrm{A}}$

A CobraPLA manufacturer's website: www.engmedsys.com/ems_ website_cobra.html. Visited in April 2006. 

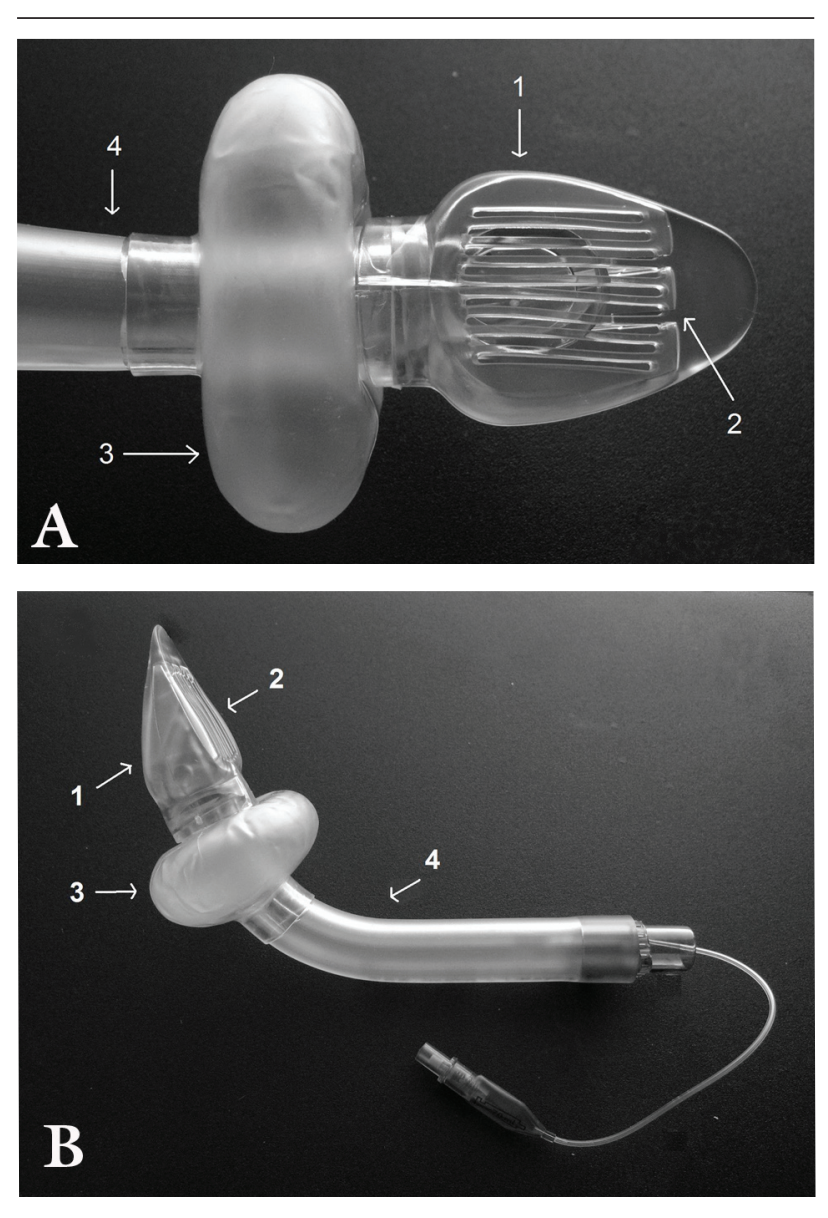

FIGURE 1A and 1B Frontal (left) and lateral (right) views of the Cobra Perilaryngeal Airway ${ }^{\circledR}$

1) Cobra head distally broadens into the shape of the head of a Cobra snake.

2) Slotted openings of the Cobra head hold both the soft tissue and the epiglottis away and permit air exchange through the openings.

3) The circumferential, large volume, low-pressure cuff is just proximal to the head and allows positive pressure ventilation up to $20 \mathrm{~cm} \mathrm{H} \mathrm{H}_{2} \mathrm{O}$

4) Breathing tube can be attached to a standard $15 \mathrm{~mm}$ internal diameter connector.

In August 2006, the original CobraPLA ${ }^{\circledR}$ was replaced with a second-generation model with a distal curve in the breathing tube to avoid kinking, and softer tubes to aid insertion and to reduce mucosal trauma (personal communication with David Alfery MD, Nashville, TN, USA; inventor of CobraPLA () ). The Cobra PLUS, which was introduced quite recently, has the added features of a temperature probe to measure core temperature and a gas sampling line for the three smallest pediatric sizes. ${ }^{12}$
TABLE I CobraPLA ${ }^{\circledR}$ size selection and characteristics of each size

\begin{tabular}{lllll}
\hline Size & Patient weight & Cuff volumes & Tube ID & Max ETT \\
\hline $1 / 2$ neonate & $>2.5 \mathrm{~kg}$ & $<8 \mathrm{~mL}$ & $5.0 \mathrm{~mm}$ & $\leq 3.0 \mathrm{~mm}$ \\
1 infant & $>5 \mathrm{~kg}$ & $<10 \mathrm{~mL}$ & $6.0 \mathrm{~mm}$ & $\leq 4.5 \mathrm{~mm}$ \\
$1-1 \mathrm{1} / 2$ child & $>10 \mathrm{~kg}$ & $<25 \mathrm{~mL}$ & $6.0 \mathrm{~mm}$ & $\leq 4.5 \mathrm{~mm}$ \\
2 child & $>15 \mathrm{~kg}$ & $<40 \mathrm{~mL}$ & $10.5 \mathrm{~mm}$ & $\leq 6.5 \mathrm{~mm}$ \\
3 adult & $>35 \mathrm{~kg}$ & $<65 \mathrm{~mL}$ & $10.5 \mathrm{~mm}$ & $\leq 6.5 \mathrm{~mm}$ \\
4 adult & $>70 \mathrm{~kg}$ & $<70 \mathrm{~mL}$ & $12.5 \mathrm{~mm}$ & $\leq 8.0 \mathrm{~mm}$ \\
5 large adult & $>100 \mathrm{~kg}$ & $<85 \mathrm{~mL}$ & $12.5 \mathrm{~mm}$ & $\leq 8.0 \mathrm{~mm}$ \\
6 large adult & $>130 \mathrm{~kg}$ & $<85 \mathrm{~mL}$ & $12.5 \mathrm{~mm}$ & $\leq 8.0 \mathrm{~mm}$ \\
\hline
\end{tabular}

$\mathrm{ETT}=$ endotracheal tube; tube ID $=$ tube internal diameter.

To insert the CobraPLA ${ }^{\circledR}$, the patient's head is placed in full extension, under general anesthesia, with the mouth open, and the mandible pulled upward. The CobraPLA $\AA$ is inserted without directing towards the hard palate and, when the tip reaches the back of the mouth, it is advanced into the hypopharynx until moderate resistance is felt. Cuff pressure is kept $<25$ $\mathrm{cm} \mathrm{H}_{2} \mathrm{O}$. Prior to removal, secretions are suctioned and the cuff is completely deflated.

With respect to contraindications, the CobraPLA ${ }^{\circledR}$ does not protect the airway against gastric regurgitation and pulmonary aspiration. Therefore, its usage should be avoided in patients with aspiration risk. ${ }^{13}$ The manufacturer recommends that the airway pressure should be limited to $<20 \mathrm{~cm} \mathrm{H}_{2} \mathrm{O} .{ }^{14}$ There is no report in the literature regarding usage of the CobraPLA ${ }^{\circledR}$ in the prone position. To avoid complications, proper sizing is recommended; and it is suggested that, when in doubt, practitioners should use the smaller size. ${ }^{15,16}$

\section{Experience from randomized controlled trials}

The CobraPLA ${ }^{\circledR}$ has been evaluated in six, randomized, controlled trials which are summarized in Table II. van Zundert et al. ${ }^{17}$ compared insertion and performance characteristics of the LMA Unique ${ }^{\mathrm{TM}}$ (The Laryngeal Mask Company, San Diego, CA, USA), the Portex ${ }^{\circledR}$ Soft-Seal ${ }^{\circledR}$ Laryngeal Mask, and the CobraPLA ${ }^{\circledR}$ in 320 patients. They evaluated the number of insertion attempts and the tactile resistance against the device; and they found that the LMA Unique ${ }^{\mathrm{TM}}$ and the Portex ${ }^{\circledR}$ Soft-Seal ${ }^{\circledR}$ laryngeal mask were easier to insert compared to the CobraPLA ${ }^{\circledR}$. However, the CobraPLA® was associated with higher endoscopic scores and better fibreoptic views of the glottis, in comparisons to other devices. While there was more frequent blood staining with the CobraPLA®, there were no other differences in morbidity. These authors 
TABLE II CobraPLA® Comparison of the randomized controlled trials

\begin{tabular}{|c|c|c|c|c|c|}
\hline Study/year & $\begin{array}{l}\text { Devicel } \\
\text { patients }(n)\end{array}$ & $\begin{array}{l}\text { Insertion } \\
\text { times (sec) }\end{array}$ & $\begin{array}{l}\text { Success at } \\
\text { first insertion }\end{array}$ & $\begin{array}{l}\text { Airway sealing } \\
\text { pressure }\left(\mathrm{cm} \mathrm{H}_{2} \mathrm{O}\right)\end{array}$ & Complications: \\
\hline vanZundert/2006 & $\begin{array}{l}\text { Cobra } 110 \\
\text { LMA-U } 107 \\
\text { SS-LM } 103\end{array}$ & $\begin{array}{l}\text { Cobra } 42 \pm 11 \\
\text { LMA-U } 40 \pm 12 \\
\text { SS-LM } 38 \pm 7 \\
P \text { not available }\end{array}$ & & $\begin{array}{l}\text { Cobra } 30 \pm 6 \\
\text { LMA-U } 25 \pm 6 \\
\text { SS-LM } 31 \pm 5 \\
P<0.001\end{array}$ & $\begin{array}{l}\text { Blood staining } \\
\text { Cobra } 54 \% \\
\text { LMA-U } 10.7 \% \\
\text { SS-LM } 9.6 \% \\
P<0.001\end{array}$ \\
\hline Kurola/2006 & $\begin{array}{ll}\text { Cobra } & 32 \\
\text { ILMA } & 32 \\
\text { LT } & 32\end{array}$ & $\begin{array}{l}\text { Cobra } 26.4 \pm 6.0 \\
\text { ILMA } 22.9 \pm 7.5 \\
\text { LT } 24.9 \pm 7.4 \\
P \text { not significant }\end{array}$ & $\begin{array}{l}\text { Cobra } 22 \% \\
\text { ILMA } 75 \% \\
\text { LT } 44 \% \\
P<0.001, \text { ILMA } \\
\text { vs Cobra }\end{array}$ & & \\
\hline Gaitini/2006 & $\begin{array}{l}\text { Cobra } 40 \\
\text { LMA-U } 40\end{array}$ & $\begin{array}{l}\text { Cobra } 26.6 \pm 7.1 \\
\text { LMA-U } 23.7 \pm 2.74 \\
P=0.02\end{array}$ & & $\begin{array}{l}\text { Cobra } 27.0 \pm 7.16 \\
\text { LMA-U } 21.0 \pm 4.21 \\
P<0.001\end{array}$ & $\begin{array}{l}\text { Blood staining } \\
\text { Cobra } 15 \% \\
\text { LMA-U } 17.5 \% \\
P=1.0\end{array}$ \\
\hline Turan/2006 & $\begin{array}{ll}\text { Cobra } & 30 \\
\text { LMA } & 30 \\
\text { LT } & 30\end{array}$ & $\begin{array}{l}\text { Cobra } 21 \pm 12 \\
\text { LMA } 20 \pm 11 \\
\text { LT } 19 \pm 14 \\
P \text { not available }\end{array}$ & $\begin{array}{l}\text { Cobra } 97 \% \\
\text { LMA } 57 \% \\
P<0.05\end{array}$ & & $\begin{array}{l}\text { Blood staining } \\
\text { Cobra } 50 \% \\
\text { LMA\&LT } 17 \% \\
P<0.01\end{array}$ \\
\hline $\mathrm{Akca} / 2004$ & $\begin{array}{l}\text { Cobra } 40 \\
\text { LMA } 41\end{array}$ & $\begin{array}{l}\text { Cobra } 38 \pm 31 \\
\text { LMA } 38 \pm 34 \\
P=0.994\end{array}$ & & $\begin{array}{l}\text { Cobra } 23 \pm 6 \\
\text { LMA } 18 \pm 5 \\
P<0.001\end{array}$ & $\begin{array}{l}\text { Gastric } \\
\text { insufflation } \\
\mathrm{cm} \mathrm{H}_{2} \mathrm{O} \\
\text { Cobra } 25 \pm 40 \\
\text { LMA } 26 \pm 25 \\
P=0.522\end{array}$ \\
\hline Gaitini/2003 & $\begin{array}{lr}\text { Cobra } & 25 \\
\text { LMA-U } & 25 \\
\text { PAX } & 25\end{array}$ & $\begin{array}{l}\text { Cobra } 16 \pm 2 \\
\text { LMA-U } 20 \pm 7 \\
\text { PAX } 30 \pm 4 \\
P \text { not available }\end{array}$ & $\begin{array}{l}\text { Cobra } 92 \% \\
\text { LMA-U } 96 \% \\
\text { PAX } \quad 80 \% \\
P \text { not available }\end{array}$ & $\begin{array}{l}\text { Cobra } 33 \pm 6 \\
\text { LMA-U } 20 \pm 5 \\
\text { PAX } 24 \pm 5 \\
P \text { not available }\end{array}$ & $\begin{array}{l}\text { Sore throat } \\
\text { Cobra \& } \\
\text { LMA } 16 \% \\
\text { PAX } \quad 20 \%\end{array}$ \\
\hline
\end{tabular}

Cobra = CobraPLA $\AA$; SS-LM = Soft Seal Laryngeal Mask; LMA = laryngeal mask airway; LT = Laryngeal Tube LT; ILMA = Intubating LMA; LMA-U = LMA Unique ${ }^{\mathrm{TM}}$; PAX = Pharyngeal Airway Xpress.

also observed that the cuff sealing pressures were higher with the CobraPLA ${ }^{\circledR}$ and the Soft Seal Laryngeal Mask $^{\mathrm{TM}}$ compared to the LMA Unique ${ }^{\mathrm{TM}}$.

Kurola $\mathrm{et} \mathrm{al.}{ }^{18}$ compared the performances of paramedical students when using the CobraPLA ${ }^{\circledR}$, the Laryngeal Tube LT, and the Intubating LMA ${ }^{\mathrm{TM}}$ in 96 patients undergoing elective surgeries. While insertion times were similar with the three devices, first time insertion success rates with the CobraPLA ${ }^{\circledR}$ were lower, as compared with the Laryngeal Tube LT and the Intubating $\mathrm{LMA}^{\mathrm{TM}}{ }^{18}$

Gaitini et al. ${ }^{19}$ compared the CobraPLA ${ }^{\circledR}$ and the LMA Unique ${ }^{\mathrm{TM}}$ in 80 healthy adults undergoing minor surgeries. Insertion times for the CobraPLA ${ }^{\circledR}$ were longer than for the LMA Unique ${ }^{\mathrm{TM}}$. While these investigators found the two devices to be similar, with respect to fibreoptic scores and the incidence of postoperative adverse events, such as blood staining or sore throat in recovery room; higher leak pressures were observed with the CobraPLA®.
Turan $e t a l .{ }^{20}$ studied the efficacy of the CobraPLA ${ }^{\circledR}$, the LMA Classic ${ }^{\mathrm{TM}}$, and the Laryngeal Tube LT in 90 healthy patients undergoing short surgical procedures. While insertion times were similar with all three devices, lower success rates, at first insertion attempt, were observed with the LMA Classic ${ }^{\mathrm{TM}}(57 \%)$, as compared to the CobraPLA ${ }^{\circledR}(97 \%)$. As with other studies, CobraPLA®s were associated with blood staining more frequently, as compared to the LMA Classic ${ }^{\mathrm{TM}}$ and the Laryngeal Tube LT.

Akca et al. ${ }^{21}$ compared the CobraPLA ${ }^{\circledR}$ and the LMA Classic ${ }^{\mathrm{TM}}$ in 81 healthy adults undergoing minor gynecologic, orthopedic, or general surgery procedures. Insertion times for the two devices were not significantly different. The CobraPLA® was found to be comparable to the LMA Classic ${ }^{\mathrm{TM}}$, with respect to airway adequacy and recovery characteristics, but superior in terms of airway sealing pressure. Also, gastric insufflation pressures with the CobraPLA $®$ were similar to pressures when using the LMA Classic ${ }^{\mathrm{TM}}$. 
TABLE III SLIPA ${ }^{\mathrm{TM}}$ - Comparison of randomized, controlled trials

\begin{tabular}{|c|c|c|c|c|c|c|c|}
\hline $\begin{array}{l}\text { Study/ } \\
\text { year }\end{array}$ & $\begin{array}{l}\text { Device } \\
\text { /Number of } \\
\text { patients (n) }\end{array}$ & $\begin{array}{l}\text { Insertion } \\
\text { Time }>15 \mathrm{sec}\end{array}$ & $\begin{array}{l}\text { Blood pressure } \\
\text { change post- } \\
\text { induction }\end{array}$ & $\begin{array}{l}\text { First insertion } \\
\text { success }\end{array}$ & $\begin{array}{l}\text { Recovery time } \\
\text { (min) }\end{array}$ & $\begin{array}{l}\text { Airway sealing } \\
\text { pressure }\left(\mathrm{cm} \mathrm{H} \mathrm{H}_{2} \mathrm{O}\right)\end{array}$ & $\begin{array}{l}\text { Complications/ } \\
\text { sore throat }\end{array}$ \\
\hline $\begin{array}{l}\text { Miller/ } \\
2006\end{array}$ & $\begin{array}{l}\text { SLIPA } 50 \\
\text { PLMA } 50 \\
\text { ETT } 50\end{array}$ & $\begin{array}{l}\text { SLIPA 0\% } \\
\text { PLMA } 18 \% \\
\text { ETT n/a } \\
P \mathrm{n} / \mathrm{s} \\
\text { SLIPA:PLMA }\end{array}$ & $\begin{array}{l}\text { SLIPA } 3.8 \% \\
\text { PLMA- } 1.2 \% \\
\text { ETT } 21.2 \% \\
P<0.001\end{array}$ & $\begin{array}{l}\text { SLIPA } 98 \% \\
\text { PLMA } 96 \% \\
P \mathrm{n} / \mathrm{a}\end{array}$ & $\begin{array}{l}\text { SLIPA } 4.8 \\
\text { PLMA } 4.7 \\
\text { ETT } 8.1 \\
P<0.001 \\
\text { ETT: SLIPA/ } \\
\text { PLMA } \\
P \mathrm{n} / \mathrm{s} \\
\text { SLIPA:PLMA }\end{array}$ & $\begin{array}{l}\text { SLIPA } 30 \\
\text { PLMA } 31 \\
\text { ETT n/a } \\
P \mathrm{n} / \mathrm{s} \\
\text { SLIPA:PLMA }\end{array}$ & $\begin{array}{l}\text { SLIPA } 49 \% \\
\text { PLMA } 30 \% \\
\text { ETT } 57 \% \\
P<0.05 \\
\text { ETT UBE: } \\
\text { PLMA }\end{array}$ \\
\hline $\begin{array}{l}\text { Miller/ } \\
2003\end{array}$ & $\begin{array}{l}\text { SLIPA } 60 \\
\text { LMA } 60\end{array}$ & & $\begin{array}{l}\text { SLIPA }-16.0 \% \\
\text { LMA }-17.8 \% \\
P=0.80\end{array}$ & $\begin{array}{l}\text { SLIPA } 92 \% \\
\text { LMA } 95 \% \\
P \mathrm{n} / \mathrm{a}\end{array}$ & & $\begin{array}{l}\text { SLIPA } 25.7 \\
\text { LMA } 23.1 \\
P=0.02\end{array}$ & $\begin{array}{l}\text { SLIPA } 45 \% \\
\text { LMA } 53 \% \\
P=0.97\end{array}$ \\
\hline
\end{tabular}

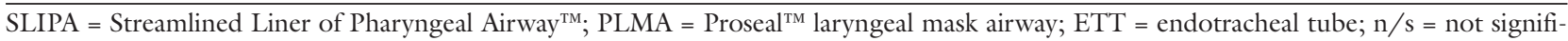
cant; $\mathrm{n} / \mathrm{a}=$ not available.

Gaitini et al. ${ }^{22}$ compared the CobraPLA®, the LMA Unique ${ }^{\mathrm{TM}}$, and the Pharyngeal Airway X press ${ }^{\mathrm{TM}}$ $(\mathrm{PAX})$ in 75 healthy individuals. The insertion times they observed with the CobraPLA ${ }^{\circledR}$ and the LMA Unique $^{\mathrm{TM}}$ were comparable, and both times were shorter than the mean insertion time observed with the $\mathrm{PAX}^{\mathrm{TM}}$. This study showed that the first attempt, insertion success rates were highest for the LMA Unique $^{\mathrm{TM}}$, followed by the CobraPLA ${ }^{\circledR}$ and the $\mathrm{PAX}^{\mathrm{TM}}$, respectively. Leak pressures were highest for the CobraPLA ${ }^{\circledR}$, followed by the PAX ${ }^{\mathrm{TM}}$ and the LMA Unique $^{\mathrm{TM}}$.

The cumulative evidence, from published, randomized, controlled trials, is that insertion times for the CobraPLA ${ }^{\circledR}$ are comparable to the LMA Classic ${ }^{\mathrm{TM}}$, the LMA Unique ${ }^{\mathrm{TM}}$, the Intubating $\mathrm{LMA}^{\mathrm{TM}}$, and the Laryngeal Tube LT; while they are shorter than insertion times for the $\mathrm{PAX}^{\mathrm{TM}}$. Three of the studies show that airway sealing pressures are higher for the CobraPLA® than for the PAX ${ }^{\mathrm{TM}}$, the LMA Unique ${ }^{\mathrm{TM}}$, and the LMA Classic ${ }^{\text {TM }} \cdot 19,21,22$

Case reports and case series evaluating the CobraPLA® Hemodynamic and respiratory variables were reported to remain stable during insertion of the CobraPLA $®$, in two preliminary studies and cohort studies involving 34 cases. $^{23-25}$ The success of the CobraPLA ${ }^{\circ}$, in achieving effective ventilation, was reported in two cases of the LMA Classic ${ }^{\mathrm{TM}}$ failure in patients with head and neck burns, contractures, limited neck extension, and limited mouth opening. ${ }^{26}$ Moreover, the CobraPLA ${ }^{\circledR}$ has been reported as being successful in the management of a difficult airway: in single cases of the Intubating LMA ${ }^{\mathrm{TM}}$ 's failure as a means of secur- ing the airway, ${ }^{27}$ for the difficult to intubate/ventilate scenario; ${ }^{28}$ and in the airway management of a neonate with Desbuquois syndrome. ${ }^{29}$ Successful, lighted, stylet-guided, tracheal intubation through a CobraPLA ${ }^{\circledR}$ has been reported, after repeated failure to intubate through an Intubating $\mathrm{LMA}^{\mathrm{TM}}$. These reports suggest that the CobraPLA ${ }^{\circledR}$ may act as an alternative rescue airway in difficult airway scenarios. There are also reports describing successful maintenance of the airway with the CobraPLA ${ }^{\circledR}$, during performance of percutaneous, dilatational tracheostomy ${ }^{24,25}$ and percutaneous cricothyroidotomy/tracheostomy. ${ }^{30,31}$ The CobraPLA ${ }^{\circledR}$ has successfully been used as a conduit for flexible bronchoscopy in a child under general anesthesia. ${ }^{32}$ There are two reports of aspiration associated with use of the CobraPLA®. ${ }^{33,34}$ Cook et al. ${ }^{33}$ reported significant pulmonary aspiration in two of 29 patients undergoing positive pressure ventilation using the CobraPLA®; and the study was terminated. Also, a case of airway obstruction, resulting from epiglottic incarceration, has been reported. ${ }^{35}$ There was an isolated report on valve leak with the device, ${ }^{36}$ although it was suggested that leaks could occur at the monitoring connection site, rather than from the device itself. ${ }^{37}$

\section{Summary of current experience with the CobraPLA®}

The CobraPLA® is a cuffed, pharyngeal sealer, supraglottic airway. The insertion times and the first pass success rates are comparable to the LMA Classic ${ }^{\mathrm{TM}}$. The CobraPLA ${ }^{\circledR}$ has been used as a primary device to maintain the airway, during spontaneous and controlled ventilation for short surgical procedures. It has been used in the intensive care unit setting for 

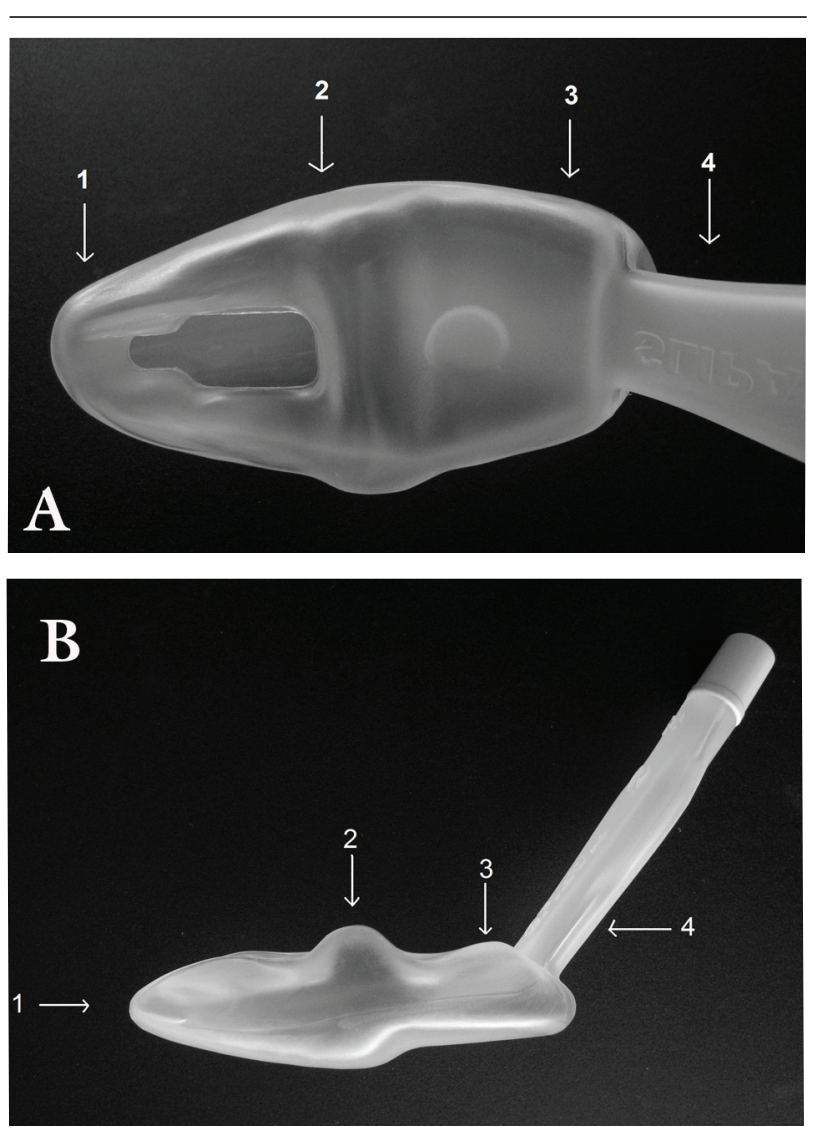

FIGURE 2A and 2B Frontal (left) and lateral (right) views of Streamlined Liner of Pharyngeal Airway ${ }^{\mathrm{TM}}$

1) The toe is positioned at the esophageal entrance.

2) The bridge seals the base of the tongue.

3) The heel sets in nasopharynx.

4) The proximal shaft is a stiffer breathing tube which leads from the body to the connector.

airway management of polytraumatized patients, for cardiopulmonary resuscitation, and for difficult airway cases, when endotracheal intubation was not possible. The CobraPLA® may be useful in patients with limited mouth opening, after failure to insert an LMA Classic $^{\mathrm{TM}}$; or when there is failure to obtain a good seal with the LMA Classic ${ }^{\mathrm{TM}}$. One case report alerts to the potential risk of significant, pulmonary aspiration. The new version, the Cobra PLUS, provides the ability of measuring $\mathrm{CO}_{2}$ and core temperature via its distal thermistor probe.

\section{The SLIPA $^{\mathrm{TM}}$}

\section{Description}

The Streamlined Liner of the Pharyngeal Airway $\left(\right.$ SLIPA $\left.^{\mathrm{TM}}\right)$ is a non-cuffed, single use, latex-free SGA, similar in design to the LMA Unique ${ }^{\mathrm{TM}}$ (Figure 2). ${ }^{11}$ It is fabricated from soft plastic (ethylenevinyl-acetate copolymer) in the shape of a pressurized pharynx. $., 38,39$ The SLIPA ${ }^{\mathrm{TM}}$ comprises a hollow, blow-moulded chamber shaped like a boot, with a toe bridge that seals at the base of the tongue and a heel that anchors the device in position between the esophagus and the nasopharynx. ${ }^{40}$ The breathing tube connects the body to a $15-\mathrm{mm}$ connector. ${ }^{41,42}$ The chamber provides a variable capacity of up to $50 \mathrm{~mL}$, for storage of regurgitated liquids from the stomach. ${ }^{40,41}$ There are six adult sizes (47-57) with a colour-coded connector. ${ }^{\mathrm{B}}$ The number (in $\mathrm{mm}$ ) indicates the width at the bridge, which is relevant to the width of thyroid cartilage. ${ }^{39,40}$ Size 47 is suitable for small women and teenagers, whereas sizes 49 and 51 are considered as the LMA Classic ${ }^{\mathrm{TM}}$ size 3 equivalents. Sizes 51 and 53 are similar to the LMA size 4 , and sizes 55 and 57 are considered similar to size $5 \mathrm{LMA}^{\mathrm{B}}$

For insertion, with the patient's head in the sniffing position and under general anesthesia, the toe is slipped into the entrance of the esophagus, where it seals against the cricopharyngeus sphincter. Obstruction, immediately after the insertion, is suggestive of down-folding of the epiglottis and should be corrected by extending the head and performing the jaw thrust maneuver. If the patient wakes up with the SLIPA ${ }^{\mathrm{TM}}$ in place, a bite block might be needed. At removal, the heel should be dislodged from the nasopharynx by pulling gently in a caudal and an anterior direction.

The SLIPA ${ }^{\mathrm{TM}}$ is not advisable for use in the prone position, when there is risk of pulmonary aspiration, and in cases of abnormal, upper airway anatomy, or when changing the head position during the surgery. ${ }^{5, \mathrm{~B}}$

\section{Clinical trial experience with the SLIPA ${ }^{T M}$}

Miller et al. ${ }^{40}$ compared the SLIPA ${ }^{\mathrm{TM}}$, the LMA Proseal $^{\mathrm{TM}}$ and standard endotracheal intubation in 150, healthy, adult females scheduled to undergo laparoscopic, gynecological procedures under general anesthesia. The insertion time was longer than 15 sec in $10 \%$ of the SLIPA ${ }^{\mathrm{TM}}$ cases and in $18 \%$ of the LMA Proseal ${ }^{\mathrm{TM}}$ cases. The investigators found that the endotracheal tube provided a superior airway seal compared to both SGAs. However, they found acceptable sealing qualities for the SLIPA ${ }^{\mathrm{TM}}$ and the LMA Proseal ${ }^{\mathrm{TM}}$ SGAs at fresh gas flow rates $<1$

B http://www.SLIPA.com/index.php/option=com content\&task. Visited in April 2006. 
$\mathrm{L} \cdot \mathrm{min}^{-1}$, without significant differences between the two devices. In contrast to the SLIPA ${ }^{\mathrm{TM}}$ and the LMA Proseal ${ }^{\mathrm{TM}}$, which had similar hemodynamic responses, endotracheal intuition was associated with an increase in systolic blood pressure > 15\% after airway instrumentation. Recovery times were shorter when using either SGA, as compared with endotracheal intubation. The combined incidence of early and late sore throats was lowest with the LMA Proseal ${ }^{\mathrm{TM}}(30 \%)$, as compared to either the SLIPA ${ }^{\mathrm{TM}}(49 \%)$ or the endotracheal intubation $(57 \%) .{ }^{40}$

Miller et $a l^{40}$ compared the SLIPA ${ }^{\mathrm{TM}}$ and the LMA Classic ${ }^{\mathrm{TM}}$ in 120 healthy adult females undergoing general anesthesia for minor gynecological procedures. Comparable first insertion success rates were found for the LMA Classic ${ }^{\mathrm{TM}}(95 \%)$ and the SLIPA $^{\text {TM }}(92 \%)$. The airway seal was sufficiently effective in both groups to permit reductions of fresh gas flow rates to $<1 \mathrm{~L} \cdot \mathrm{min}^{-1}$. Blood pressure alterations, during airway management, were minor with either device. The SLIPA ${ }^{\mathrm{TM}}$ was associated with sore throats in $45 \%$ of patients vs $53 \%$ of patients with the LMA Classic ${ }^{\mathrm{TM}} .{ }^{41}$ Miller et al. ${ }^{38}$ also reported, from a small pilot study of 22 patients evaluating use of the SLIPA $^{\mathrm{TM}}$, that insertion times took longer than ten seconds and oxygen saturation decreased to $<95 \%$ in only $4.5 \%$ of the cases.

Hein et al. ${ }^{39}$ undertook a clinical trial on 60 patients, to assess the insertion success and effectiveness of SLIPA ${ }^{\mathrm{TM}}$, and observed a first-time insertion success rate of $85 \%$ in group A (principal investigator) and $90 \%$ in group B (medical officers and anesthesiologists). The lowest oxygen saturation was $93 \%$ in group A and $91 \%$ in group B. After a second attempt at insertion, the overall success rate was $100 \%$ in group A compared to $92.5 \%$ in group B. The overall incidence of sore throat (score $>0$ ) and blood on the device was reported. Twenty-three percent of patients experienced sore throat, which was described as mild in the majority of cases. Overall, the SLIPA ${ }^{\mathrm{TM}}$ was reported as being reliable and easy to use in both spontaneous and assisted ventilation. Coetzee et al..$^{42}$ reported an in vitro study where a flow rate of 30 $\mathrm{L} \cdot \mathrm{min}^{-1}$ was generated through the device. There was no significant change in pressure between the two ends of the airway, suggesting that the SLIPA ${ }^{\mathrm{TM}}$ would not create turbulent flow at the described flow rates.

\section{Summary of current experience with the SLIPA ${ }^{T M}$}

The SLIPA $^{\mathrm{TM}}$ is a single use, latex-free, non-cuffed SGA. It is intended for use as a primary airway device for short surgical procedures, ${ }^{39}$ for which the SLIPA ${ }^{\mathrm{TM}}$ has similar efficacy and complications, as compared to the LMA Classic ${ }^{\mathrm{TM}}$. Even though the SLIPA ${ }^{\mathrm{TM}}$ has a chamber with a capacity of approximately 50 $\mathrm{mL}$, which most often exceeds the volume of gastric contents in fasted patients, its efficacy in prevention of aspiration has yet to be proven. More clinical evidence is needed to determine the potential reduction of aspiration risk associated with the SLIPA ${ }^{\mathrm{TM}}$. As the overall incidence of gastric aspiration is low, it is likely that surveillance studies will provide the best available evidence.

There are several limitations of this review. The few reported, randomized, controlled trials contain relatively small sample sizes; and not all reports provided clear, sample size calculations to justify their sample size requirements. Secondly, the potential for observer bias must be recognized, as the lead author of two studies was also one of the developers of the device. ${ }^{40,41}$ Thirdly, in several of the cited studies, ${ }^{40,41}$ SGA insertions were performed by anesthesiologists who had a large cumulative experience with SGAs. Conclusions drawn from these studies may not be broadly applicable to anesthesiologists who use these devices less frequently.

\section{Conclusions}

Over the past decade, a number of new SGAs have been introduced as alternatives to the LMA Classic ${ }^{\mathrm{TM}}$. The overall efficacy of the CobraPLA® is comparable to that of the LMA Classic ${ }^{\mathrm{TM}}$, with a similar reported complication rate. Notably, the CobraPLA® is designed for single use and provides better airway sealing compared to the LMA Classic ${ }^{\mathrm{TM}}$. The SLIPA ${ }^{\mathrm{TM}}$ also has an efficacy and favourably low complication profile, similar to that of the LMA Classic ${ }^{\mathrm{TM}}$. A distinguishing feature of the SLIPA ${ }^{\mathrm{TM}}$ is its unique reservoir chamber, which may, in theory, reduce the risk of pulmonary aspiration. Considering the limited number of subjects who have been evaluated in comparative clinical trials, further studies with larger numbers of patients are warranted, to determine the best SGA with regards to efficacy and safety.

\section{References}

1 American Society of Anesthesiologists Task Force on Management of the Difficult Airway. Practice guidelines for management of the difficult airway: an updated report by the American Society of Anesthesiologists Task Force on Management of the Difficult Airway. Anesthesiology 2003; 98: 1269-77.

2 Henderson JJ, Popat MT, Latoo IP, Pearce AC; Difficult Airway Society. Difficult airway society guidelines for management of the unanticipated difficult intubation. Anaesthesia 2004; 59: 675-94. 
3 Inoue $T$. Recent advances in airway management devices (Japanese). Masui 2006; 55: 5-12.

4 Crosby E. The unanticipated difficult airway - evolving strategies for successful salvage. Can J Anesth 2005; 52: 562-7.

5 Miller DM. A proposed classification and scoring system for supraglottic sealing airways: a brief review. Anesth Analg 2004; 99: 1553-9.

6 Verghese C, Brimacombe JR. Survey of laryngeal mask airway usage in 11,910 patients: safety and efficacy for conventional and nonconventional usage. Anesth Analg 1996, 82: 129-33.

7 Miller DM, Youkhana I, Karunaratne WU, Pearce A. Presence of protein deposits on 'cleaned' re-usable anaesthetic equipment. Anesthesia 2001; 56: 1069-72.

8 Rich JM, Mason AM, Bey TA, Krafft, Frass M. The critical airway, rescue ventilation, and the combitube: Part 1. AANA J 2004; 72: 17-27.

9 Asai $T$, Shingu $K$. The laryngeal tube. Br J Anaesth 2005; 95: 729-36.

10 Hung $O$, Law $J A$. Advances in airway management. Can J Anesth 2006; 53: 628-31.

11 Brimacombe J. A proposed classification system for extraglottic airway devices. Anesthesiology 2004; 101: 559.

12 Wadhwa A, Sessler DI, Sengupta P, Hanni K, Akca O. Core temperature measurements through a new airway device, perilaryngeal airway (CobraPLA). J Clin Anesth 2005; 17: 358-62.

13 Quinn B. The CobraPLA - a response from the manufacturer. Anaesthesia 2005; 60: 817-8.

14 Cook TM, Lowe J. More on the CobraPLA. Anaesthesia 2005; 60: 1144-5.

15 Alfery DD, Ghelber Ezri T, Szmuk P. Correct sizing of the CobraPLA is necessary for valid study results. Eur J Anaesthesiol 2006; 23: 714-5.

16 Alfery D, Ezri T, Ghelber O, Szmuk P. Teaching airway management is dependent on the knowledge of the teachers. Acta Anaesthesiol Scand 2006; 50: 895-6.

17 van Zundert A, Al-Shaikh B, Brimacombe J, Koster J, Koning D, Mortier EP. Comparison of the three disposable extraglottic airway devices in spontaneously breathing adults: the LMA-Unique, the Soft Seal laryngeal mask, and the Cobra perilaryngeal airway. Anesthesiology 2006; 104: 1165-9.

18 Kurola J, Pere P, Neimi-Murola L, et al. Comparison of airway management with the intubating laryngeal mask, laryngeal tube and CobraPLA by paramedical students in anaesthetized patients. Acta Anaesthesiol Scand 2006; 50: 40-4.

19 Gaitini L, Yanovski B, Somri M, Vaida S, Riad T, Alfery D. a comparison between the PLA Cobra and the Laryngeal Mask Airway Unique during spontane- ous ventilation: a randomized prospective study. Anesth Analg 2006; 102: 631-6.

20 Turan A, Kaya G, Koyuncu O, Karamanlioglu B, Pamukcu Z. Comparison of the laryngeal mask (LMA) and laryngeal tube LT (LT) with the new perilaryngeal airway (CobraPLA) in short surgical procedures. Eur J Anaesthesiol 2006; 23: 234-8.

21 Akca $O$, Wadhwa A, Sengupta $P$, et al. The new perilaryngeal airway (Cobra PLA) is as efficient as the laryngeal mask airway (LMA) but provides better airway sealing pressures. Anesth Analg 2004; 99: 272-8.

22 Gaitini LA, Somri M.J, Kersh K, Yanovski B, Vaida S. A comparison of the Laryngeal Mask Airway Unique ${ }^{\mathrm{TM}}$, Pharyngeal Airway X press ${ }^{\mathrm{TM}}$ and Perilaryngeal Airway Cobra $^{\mathrm{TM}}$ in paralyzed anesthetized adult patients. Anesthesiology 2003; 99: Al495 (abstract).

23 Agro F, Barzoi G, Carassiti M, Galli B. Getting the tube in the oesophagus and oxygen in the trachea: preliminary results with the new supraglottic device (Cobra) in 28 anaesthetised patients. Anaesthesia 2003; 58: 920-1.

24 Agro F, Carassiti M, Magnani C, Alfery D. Airway control via the CobraPLA during percutaneous dilatational tracheostomy in five patients. Can J Anesth 2005; 52: 418-20.

25 Agro F, Carassiti M, Magnani C. Percutaneous dilatational cricothyroidotomy: airway control via CobraPLA. Anesth Analg 2004; 99: 628.

26 Khan RM, Maroof M, Johri A, Ashraf M, Jain D. Cobra PLA can overcome LMA failure in patients with face and neck contractures. Can J Anesth 2005; 52: 340 .

27 Dimitriou V, Brimacombe J, Zogogiannis I, Voukena V, Malefaki A, Voyagis GS. Success of the Cobra after failure of the Fastrach in the difficult airway. Can J Anesth $2005 ; 52: 992$.

28 Szmuk P, Ezri T, Akca O, Alfery DD. Use of a new supraglottic airway device - the CobraPLA - in a 'difficult to intubate/difficult to ventilate' scenario. Acta Anaesthesiol Scand 2005; 49: 421-3.

29 Szmuk P, Matuszczeak M, Carlson RF, Warters RD, Rabb MF, Ezri T. Use of CobraPLA for airway management in a neonate with Desbuquois syndrome. Case report and anesthetic implications. Paediatr Anaesth 2005; 15: 602-5.

30 Cook TM. Use of the CobraPLA for percutaneous cricothyroidotomy and tracheostomy. Anesth Analg 2005; 100: 902 .

31 Agro F, Carassiti M, Mangani C. Use of the CobraPLA for percutaneous cricothyroidotomy and tracheostomy. Anesth Analg 2005; 100: 902-3.

32 Szmuk P, Ghelber O, Akca O, Ezri T. CobraPLA as a conduit for flexible bronchoscopy in a child under gen- 
eral anaesthesia. Br J Anaesth 2005; 94: 548-9.

33 Cook TM, Lowe JM. An evaluation of the Cobra perilaryngeal airway: study halted after two cases of pulmonary aspiration. Anaesthesia 2005; 60: 791-6.

34 Farrow C, Cook T. Pulmonary aspiration through a Cobra PLA. Anaesthesia 2004; 59: 1140-1.

35 ramaguchi S, Urabe K, Ikeda T, Kitajima T. Airway obstruction due to incarceration of the epiglottis into the epiglottic bars during general anesthesia with a new perilaryngeal airway (CobraPLA). Anesth Analg 2006; 102: 973.

36 van Zundert A, Baha AS, Brimacombe J, Mortier E. Valve leaks with new disposable extraglottic airway devices. Anesthesiology 2005; 103: 213.

37 Quinn B. Valve leaks with new disposable extraglottic airway devices. Anesthesiology 2003; 103: 214.

38 Miller DM, Lavelle $M$. A streamlined pharynx airway liner: a pilot study in 22 patients in controlled and spontaneous ventilation. Anesth Analg 2002; 94: 75961.

39 Hein C, Plummer J, Owen H. Evaluation of the SLIPA (Streamlined liner of the pharynx airway), a single use supraglottic airway device, in 60 anaesthetized patients undergoing minor surgical procedures. Anaesthesia and intensive care 2005: 33: 756-61.

40 Miller DM, Camporota L. Advantages of Proseal and SLIPA airways over tracheal tubes for gynecological laparoscopies. Can J Anesth 2006; 53: 188-93.

41 Miller DM, Light D. Laboratory and clinical comparisons of the Streamlined Liner of the Pharynx Airway (SLIPA) with the laryngeal mask airway. Anaesthesia 2003; 58: 136-42.

42 Coetzee GJ. Flow through disposable alternatives to the laryngeal mask. Anaesthesia 2003; 58: 280-1. 